\title{
原子層制御したシリコン三次元立体表面構造の創製・観察技術
}

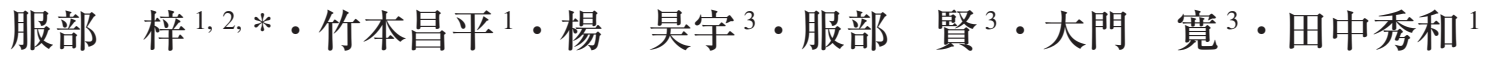 \\ 1 大阪大学産業科学研究所 産業科学ナノテクノロジーセンター 矛 567-0047 大阪府茨木市美穂ケ丘 8-1 \\ ${ }^{2}$ JST さきがけ 齿332-0012 埼玉県川口市本町 4-1-8 \\ 3 奈良先端科学技術大学院大学 物質創成科学領域 凿 630-0192 奈良県生駒市高山町 8916-5
}

（2019 年 2 月 15 日受付；2019 年 4 月 2 日掲載決定）

\section{Development of Methods of Creating and Observing Atomically-ordered Side-surfaces on Three-dimensionally Architected Si Substrates}

\author{
Azusa N. Hattori ${ }^{1,2, *}$, Shohei Takemoto ${ }^{1}$, Haoyu Yang $^{3}$, Ken Hattori ${ }^{3}$, Hiroshi Daimon ${ }^{3}$ and Hidekazu Tanaka ${ }^{1}$ \\ ${ }^{1}$ Nanoscience and Nanotechnology Center, The Institute of Scientific and Industrial Research, Osaka University, \\ 8-1 Mihoga-oka, Ibaraki, Osaka 567-0047 \\ ${ }^{2}$ JST-PRESTO, 4-1-8 Honcho, Kawaguchi, Saitama 332-0012, Japan \\ ${ }^{3}$ Graduate School of Science and Technology, Nara Institute of Science and Technology, 8916-5 Takayama, Ikoma, Nara 630-0192
}

(Received February 15, 2019 ; Accepted April 2, 2019)

\begin{abstract}
We have established the original methodology that enable to observe atomic orderings and arrangements of "surfaces with arbitrary directions" on 3D figured structures, by developing diffraction and microscopy techniques. An original technique, namely, the directly and quantitatively viewing of the side- and facet-surfaces in atomic scale using reflection high-energy electron diffraction (RHEED) and scanning tunneling microscope (STM), can feedback to the determination of process parameters in the etching procedure. The scientifically optimized etching recipe enabled the creation of atomically-ordered side-surfaces, which are perpendicular to planar substrate surfaces on 3D patterned $\mathrm{Si}$ substrates. RHEED and STM prove atomically-reconstructed $\operatorname{Si}\{100\} 2 \times 1,\{110\} 16 \times 2$, and $\{111\} 7 \times 7$ side-surfaces that were realized for the first time. We have also developed the atomically-ordered 3D nanofabrication technique, where the material stacking direction is switched from the general out-of-plane to in-plane direction, and realized the formation ultra-thin epitaxial films in 3D space.
\end{abstract}

KEYWORDS : side surface, 3D structure, RHEED, STM

\section{1.は じ め に}

スマートフォンに代表されるように, 情報機器が急速 に発展・普及しネットワーク社会が実現されている。こ れは主にシリコンテクノロジーの発展のおかげである。 現在のシリコンデバイスのゲート長は $10 \mathrm{~nm}$ (原子約 100 個分）程度まで減少し，デバイスの形状は二次元 （2D）平面上から, 例えば Fin-FET など垂直方向に積み あがる三次元（3D）立体構造になってきた1)。三次元立 体構造での特性の維持には, 電子伝導パスとなる表面領

\footnotetext{
*E-mail : a-hattori@sanken.osaka-u.ac.jp
}

域に，原子配列の乱れが生じていないことが求められ る。つまり, ナノエレクトロニクスの重要性が増す中 で, 精密制御された $3 \mathrm{D} ナ ノ$ 構造体が求められているわ けである。当然であるが, $3 \mathrm{D}$ 構造体上には, 研磨され たウェハの一般的な $2 \mathrm{D}$ 平面表面だけでなく，製造され た構造の垂直および斜面など，異なる配向を有する多く の 3D 表面がある（Fig. 1)。3D 化しても材料成長は常 に表面で始まるので, 側面は構造的および物理的特性の 決定において重要な役割を果たす。この 3D 側面の精密 制御に必要なのが, これまで $2 \mathrm{D}$ 平面で培われてきた表 面科学である。

シリコン表面の研究は, $\operatorname{Si}(111) 7 \times 7^{2)}, \quad \operatorname{Si}(100) 2$ 


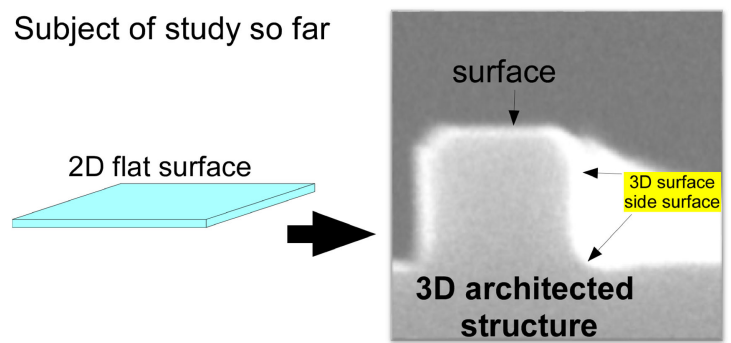

Fig. 1. (color online). Concept of our approach toward realizing atomically ordered 3D structure.

$\left.\times 1^{3)}, \quad \mathrm{Si}(110) 16 \times 2^{4}\right)$ 再構成表面の原子構造の決定を初 めとして, Si 表面上の吸着構造 ${ }^{5}$ など，様々な表面にお いて行われている。2D 表面構造は, 原子レベルで作製, 修節, 構造評価ができる技術が確立している。一方, 3D 構造になると評価方法が限られ, 精度や沉用性が極 端に低くなる。3D ナノ構造体の構造観察に一般的に使 用される走查電子顕微鏡（SEM）は, ナノメートル程度 の分解能しかないため精密な評価はできず，原子分解能 をもつ透過電子顕微鏡（TEM）は，観察用の試料準備 が必要で，また正面から側面表面を観察することは原理 的にできない。

そこで，我々は以下に示すように，空間的にデザイン した観察用試料を用意し装置の干渉を回避することで, 三次元表面である「側面」や「ファセット斜面」の構造 評価を実現した。具体的には, 表面構造計測技術である 回折法や顕微鏡技術の三次元展開に取り組んだわけであ る。このアプローチは単純な発想で，一見すぐに実現で きそうに思うが, 次元性の向上による複雑さが増加し, 装置等の制約のため三次元的な観察は簡単ではない。こ れまでは SEM などの間接的で精度がせいぜい数 $\mathrm{nm}$ と いう側面構造のラフネス評価を, 立体表面構造の原子オ ーダー直接観察技術は, 直接的にかつ原子 1 個分の 0.1 $\mathrm{nm}$ の精度で原子構造の観察を可能とし, 経験的に発展 してきた三次元立体加工技術のパラメーター制御へとフ イードバックすることが出来た。本報告では, 反射高速 電子線回折 (Reflection High Energy Electron Diffraction, RHEED）と走查型トンネル顕微鏡（Scanning Tunneling Microscope, STM）を用いた 3D 側面を評価する手法の紹 介と, 初めて実現した清浄側面構造, さらに物性研究一 と展開した研究結果を示す。

\section{2. 立体側面の作製と構造評価 ${ }^{10 ~ 12) ~}$}

まず初めに，立体 $\mathrm{Si}$ 構造の作製手法を簡単に示す。 $\mathrm{Si}$ の造形に関しては工業的な需要から, ドライエッチン グ，ウェットエッチングを用いて多くの報告がなされて
いる。ボッシュ法吕に代表されるように，ドライエッチ ングの多くは反応性イオンエッチング (reactive ion etching, RIE）で行われている。RIE はウエハ（基板）に 対してイオンが垂直に入射するため, 異方性のエッチン グになり寸法制御性に優れており，サイズ・形状制御 性，生産性など，工業的な視点からパラメーターの制御 の取り組みがなされている。今回のように原子レベルで の制御となると, 原子レベルでの反応素過程の理解が必 要となる。詳細は割愛するが，任意の側面を作製するの に・原子拡散長（反応の異方性度を決める），・エッチ ング/パッシベーションの反応均衡（側面形状を決め る），・クラスター運動エネルギー（側面の原子配列の 乱れを決める）といった物理量を制御する必要がある。 この物理量とプロセスパラメー夕：基板温度, ガス圧, 印加電圧，ガス種などの関係を解明し7)，RIE 条件を決 定した。構造観察に用いた試料は，市販の鏡面研磨され た $\mathrm{Si}$ 基板上に $3 \mathrm{D}$ 構造を設計，作製したものである。フ オトリソグラフィーでマスクパターンを描画した後， $\mathrm{Si}$ を誘導結合プラズマ（ICP） 反応性イオンエッチングシ ステム（RIE-400iPB，Samco）でエッチングした。プロ セスパラメータは, $300 \mathrm{~W}$ の ICP 源電力, $10 \mathrm{~W}$ のバイ アス電力，㧍よび $4 \mathrm{~Pa}$ の使用圧力であった。エッチン グサイクルでは $10 \mathrm{sccm}-\mathrm{SF}_{6}, \quad 5 \mathrm{sccm}-\mathrm{O}_{2}$, 扔よび 200 sccm-Arを使用し，パッシベーションプロセスでは 40 sccm- $\mathrm{C}_{4} \mathrm{~F}_{8}, \quad 5$ sccm- $\mathrm{O}_{2}$ ，および $200 \mathrm{sccm}-\mathrm{Ar}$ の混合ガス をそれぞれ使用した。この RIE 条件は，基板表面/側面 の面方位に関係なく垂直な側面を切り出せる。RIE 直後 の側面ラフネスは数 $\mathrm{nm}$ 程度ある。仕上げとして，アル カリエッチング液を用いて側面ラフネスを $0.5 \mathrm{~nm}$ 以下 にした。この際は, 側面の結晶面によって濃度や時間の 制御が必要となる。

RHEED は高速の電子線を試料表面に浅い角度で入射 させ，試料表面の結晶格子で回折した反射図形を検出す ることで結晶表面の状態を調べる分析手法である ${ }^{8)}$ 。原 理的に RHEED ではすべての方向への反射回折像取得が 可能であるが，そのためには試料（もしくは電子線）回 転機構が必要となる。我々の RHEED 装置9)では, 試料 の傾斜，面内回転が可能である。空間的にデザインした 観察用試料を用意する事で，試料に対して視斜角： $\theta$, 方位角： $\phi$ を制御した RHEED 観察（Fig. 2 (a)）を行 った。

原子分解能をもつ STM は正面から表面原子配列構造 を観察する有用な評価法だが，通常の三次元立体加工側 面では，その幾何学的配置関係から顕微プローブ（STM チップ）は下地基板と干渉するため, 観察は不可能であ る。それを三次元立体加工にサブミリメートルの深堀技 
(a)

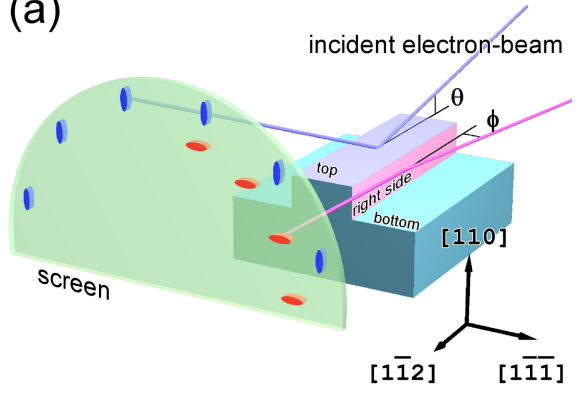

(b)

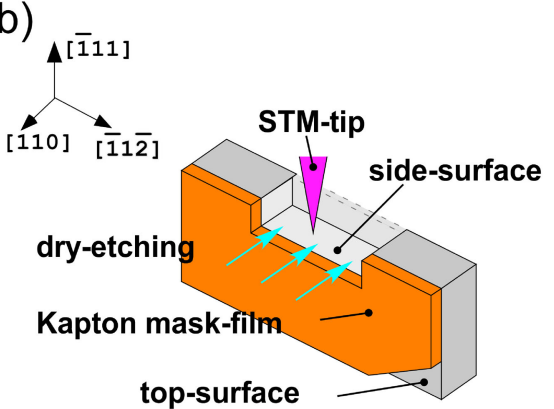

(c)

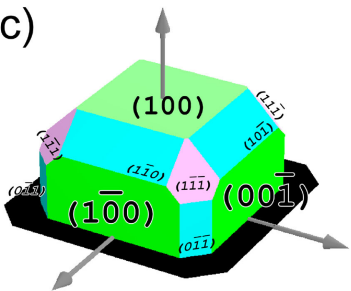

(d)

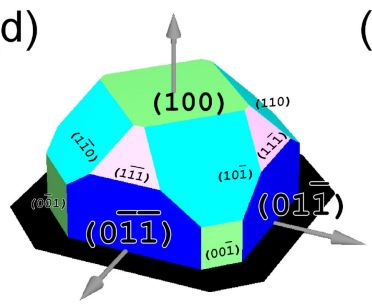

(e)

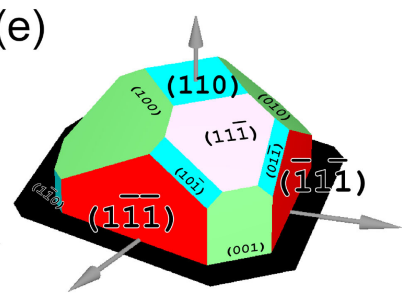

Fig. 2. (color online). (a) Schematic of the diffraction from the top and side surfaces of the 3D-patterned $\mathrm{Si}(110)$ substrate. Adapted from Ref 10. (b) Schematics of STM-tip approaching the (111) side-surface. Adapted from Ref 11. (c)-(e) Schematic of relationship between surface and side surface.

(a)
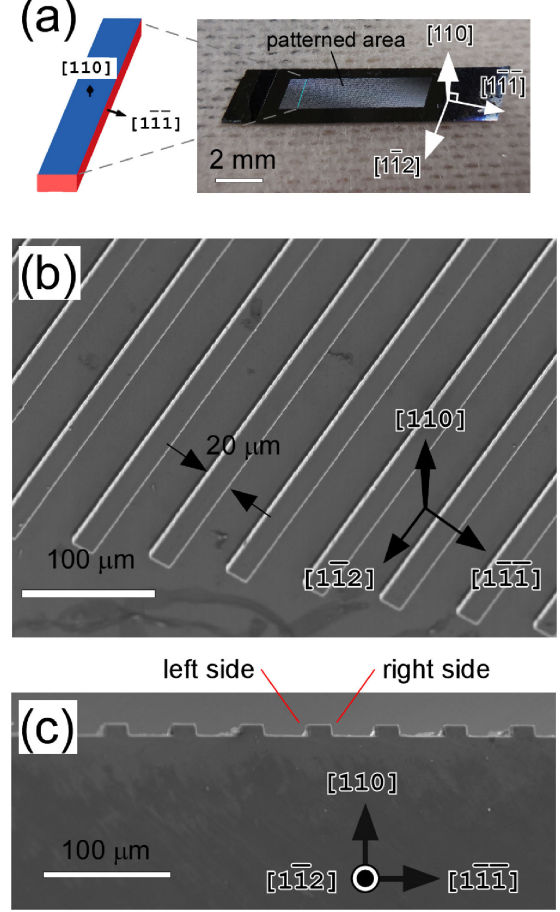

Fig. 3. (color online). (a) Photograph of a 3D-patterned Si(110) substrate. (b) Top-view and (c) cross-sectional SEM images of a patterned area of the 3D Si. Adapted from Ref 10.

術を併用することにより顕微プローブの干渉問題を回避 し，STM を用いたシリコン側面表面の原子スケールで の評価を実現した（Fig. 2（b)）。Fig. 3 (a) に，本研究 で作成した $\{111\}$ 側面を持つ $3 \mathrm{D}-\mathrm{Si}$ 試料を示す。グレー
部分が 3D パターンを施した領域である。ラインは

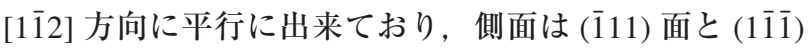
面で構成されている（Fig. 3 (b)，(c))。RHEED，STM 観察は, 3D パターン後の試料を SPM 洗浄し, 超高真空 チャンバーに導入し，フラッシングアニールで清浄化し た後に行った。

\section{3. 結果と考察}

我々は $\mathrm{Si}$ の主要な三つの面（Fig. 2 (c)-(e)) である $\{100\} 2 \times 1 ，\{110\} 16 \times 2 ，\{111\} 7 \times 7$ の側面構造作製と 観察に成功している。本稿では紙面の都合上, $\{111\}$ 側 面の結果のみ示す。また, 今回用いた RHEED の電子線 のスポットサイズは $\phi=0.5-1.0 \mathrm{~mm}$ であるため, 照射 領域内にある側面からの平均の情報を観察していること を申し添えておく。

\section{3. $1 \mathrm{Si}(111)$ 側面構造の実現 ${ }^{10 ~ 12)}$}

側面 $\{111\} 7 \times 7$ が形成されれば，当然であるが表面科 学の研究者にとって馴染み媣い $7 \times 7$ 構造が RHEED で も STM でも観察されるわけである。最適化条件で 3D パターン化し， $\{111\}$ 側面を持つ $3 \mathrm{D}-\mathrm{Si}$ の $1470 \mathrm{~K}$ フラッ シング後の RHEED 像の一例を Fig. 4 (a)-(c) に示す。 見慣れた $7 \times 7$ 回折パターンが, 不思議な形で観察され ていることにすぐに気づくのではないだろうか。なぜな ら通常の半円状ではないからである。詳しく見ていく と, Fig. 4 (a) では半円状の表面からの回折と同時に, 左の $1 / 4$ 円の側面からの回折像の重站わせが見えてい 

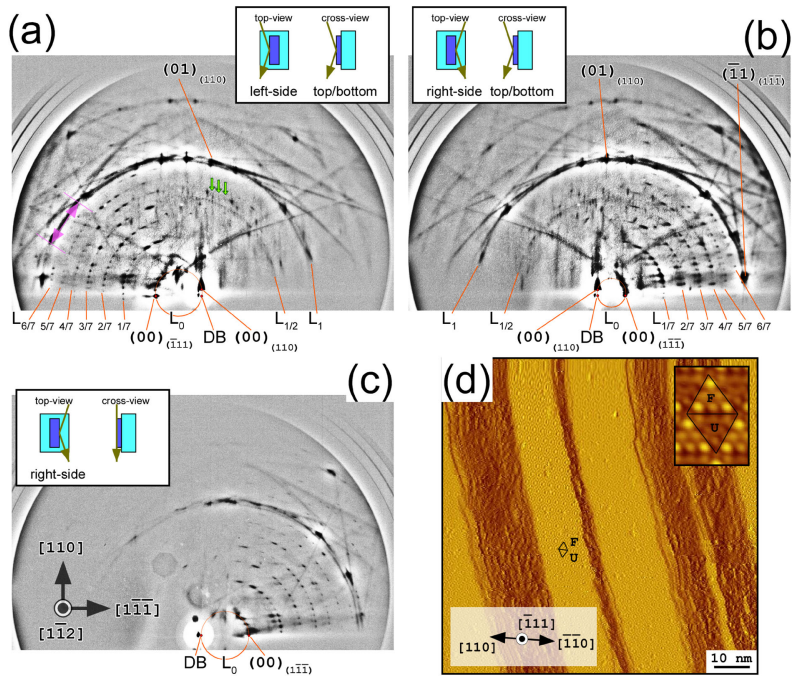

Fig. 4. (color online). RHEED patterns of the 3D-Si diffracted from (a) top and left side-surface, (b) top and right side-surface and (c) right side-surface. Adapted from Ref 10. (d) Spatial-derivative STM images with $100 \times 100 \mathrm{~nm}^{2}$. Adapted from Ref 11 .

る。これらのパターンは，それぞれ表面からの $\mathrm{Si}(110)$ $16 \times 2$ 超構造と側面からの $\operatorname{Si}\{111\} 7 \times 7$ 構造を示してい る。側面からの回折は $\mathrm{Si}(110)$ 表面がシャドウエッジと なるため $1 / 4$ 円状で, 電子線が照射される左側だけに現 れている。これが，表面に対して「垂直」である側面の 配置に由来する特徵である。もう一つすぐわかる特徽 は，垂直方向に伸びる表面からの回折スポットに対し て，側面からの回折スポットは水平方向に少し伸びてい ることである。一般的に, 回折スポットの伸びる方向は 表面垂直方向であり，表面が基板表面に対して $90^{\circ}$ 回転 している側面では, 当然スポットが伸びる方向も $90^{\circ}$ 回 転する。これらの結果は, 基板表面 (110) に加えて, 左 側に表面に対して垂直な (11̄̄1) 面が存在していることを 示している。

RHEED の回折条件 $\left(-0.6^{\circ} \leqq \theta \leqq+1.4^{\circ},-4.5^{\circ} \leqq \phi \leqq\right.$ $\left.+4.7^{\circ}\right)$ に依存して, アクセスできる面，つまり回折像 が得られる表面が異なる ${ }^{10)}$ 。Fig. 4 (b) では, 右側面と 表面からの回折像の重ね合わせ, Fig. 4 (c) では視射角 を小さくしたため表面からは回折がおこらず，左側面か らの回折パターンのみ観察している。視射角と方位角に 依存した種々の RHEED 像は, 論文 [10］の Apeendix でご覧いただける。これらの結果は，表面に垂直な側面 が存在していることを示しており，側面構造の RHEED 観察に初めて成功した例である。3D パターン構造を作 製していれば，側面からの RHEED パターンは得られる ものの, RIE 条件が不適切だと $7 \times 7$ 構造は得られない。 ただ構造を切り出せばよいわけではないことを, 強調し
ておく。

さて，側面 RHEED 像を見てみると，ダイレクトビー ム（DB）からの反射スポット（00）が左右に現れてい ること，菊池バンドや帯が強く現れていることから，作 製した 3D-Si(110) 試料の側面は原子レベルで平坦である ことを示している。RHEED は平均的な構造を表してい るが，直接原子構造も STM で観察できている。Fig. 4 (d) は Si(111) 側面の STM 像を示している。明るい部分 は原子レベルで平坦な $7 \times 7$ テラスを，暗い部分はステ ップ束を示しており，Si(111) 表面と同様のステップ-テ ラス構造が確認出来ている。挿入図では $7 \times 7$ 構造の積 層欠陥 (stacking fault) がある部分とない部分が明瞭に 見えている。

以上のように, 我々は表面, 側面の両方を原子レベル で制御した 3D-Si 構造を初めて実現したと言える。

\section{2 原子層精度での 3D 立体造形 ${ }^{10,12)}$}

$3 \mathrm{D}$ 構造材料の表面・側面両方の原子レベルでの制御 は，これまで実現していなかった立体造型と物性研究を 可能とする。表面，側面の両方を原子レベルで制御した 3D 構造は，これまでデバイスの積層土台である基板構 造を二次元平坦から三次元立体構造への転換を可能とす るからである。側面を物質成長の起点とすれば，物質の 積層方向をこれまでの基板垂直方向だけでなく，面内方 向（=側面垂直方向）へと転換してへテロ構造を作製す ることができる。側面構造創製のデモンストレーション として， $\{111\} 7 \times 7$ 側面上へ金属を蒸着することで, 超 構造の作製を行った。金属蒸着の際は，側面に対して直 入射（表面に対して斜入射）になるように試料を配置し て，左右の側面にそれぞれ異なる金属種を蒸着した。 Fig. 5 (a)，（b）は $\mathrm{Si}\{111\}$ 清浄側面に $0.2 \mathrm{~nm}-\mathrm{Fe}$ と 1 $\mathrm{nm}-\mathrm{Ag}$ を室温で蒸着し, 蒸着後に $773 \mathrm{~K}$ で加熱を施し RHEED 観察した結果である。鉄を蒸着した左側面上で は $2 \times 2$ 超構造が確認できる。一方, 銀を蒸着した右側 面からの回折像は $\sqrt{3} \times \sqrt{3}$ 超構造が確認できている。 このように通常の二次元平面表面上と同様に, 側面でも 金属吸着超構造の作製は可能である。さらに, 左右それ ぞれの側面の断面 TEM 像を Fig. 5 (c)，（d）に示す。 どちらの側面においても Si と蒸着金属との界面が明暸 に観察され，原子レベルの精度で乱れのない整列した金 属超薄膜を作製できていることがわかる。これは 2D で の構造作製技術が $3 \mathrm{D}$ 表面でも出来るという，当然では あるが，格段に難しい技術が達成されていることを意味 している。

\section{3 立体構造由来の物性研究：ファセット端での伝 導特性 ${ }^{16)}$}

最後に，原子精度の立体造形技術を用いることで実現 


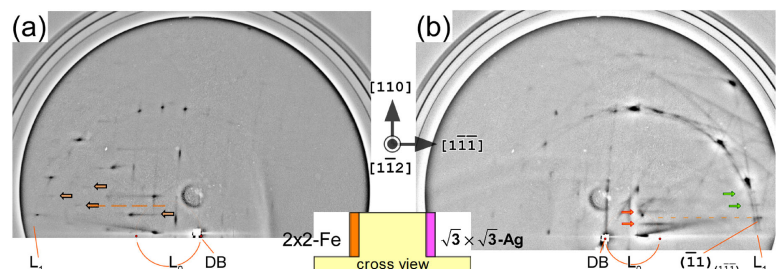

(c)

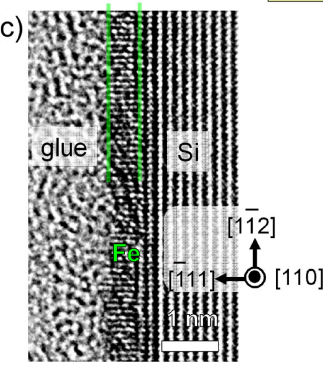

(d)

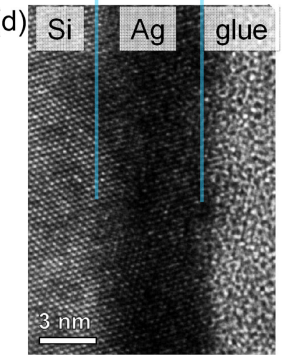

Fig. 5. (color online). Typical RHEED patterns obtained from (a) $2 \times 2-\mathrm{Fe}$ on $\mathrm{Si}(1 \overline{1} \overline{1})$ left side-surface and (b) $\sqrt{3} \times \sqrt{3}-\mathrm{Ag}$ on $\mathrm{Si}(\overline{1} 11)$ right side-surface. Cross-sectional TEM images of (c) Fe-deposited on left side-surface and (d) Ag-deposited on right side-surface. (a) and (c) adapted from Ref 12 .

した物性研究例を紹介する。三次元立体構造にした FinFET では，加工寸法が nm オーダーに入ってきており， デバイス性能向上にはその立体構造上に施された金属電 極配線の高性能化も必須である。立体構造上では立体上 の面間をつなぐ金属配線の接続が必然的に不連続になる が, これまでの電極伝導特性の評価は二次元平面基板上 に限られておりり ${ }^{13 \sim 15)}$, 立体配線の評価は行われていな い。立体構造に由来する伝導特性を明らかにするために は, 抵抗上昇の要因となるラフネスなどの乱れがない精 密に制御された試料が必要だが, 試料作製の困難さなど から，これまでに原子レベルで精密に制御された $3 \mathrm{D}$ 立 体上の金属配線の伝導特性評価はなされていなかったの である。
我々の実現した原子レベルで乱れの無い表面/側面を 持つ 3D-Si 構造（Fig. 3）は必要条件を満たしてはいる が，表面-側面をまたぐように電極を作製し，計測する のはやや困難である。そこで, 表面に対して傾斜のある 傾斜 $\{111\}$ 面に注目し, その傾斜面を横切るように電極 構造を作製することにした。具体的には, $\mathrm{Si}(110)$ 上の \{111\}facet 面（Fig. 2 (e)）を, 垂直側面と同様の加工技 術を用いて作製した。Fig. 6 (a)，（b）に $\mathrm{Si}(110)$ 基板上 に原子レベルで平坦かつ欠陥のないファセット $\{111\}$ 構 造を示す。この 3D-facet 面は (110) 表面に対し 35.3の傾 斜角をもつ(111) 面, (111) 面で構成されており, 平坦な 傾斜面が形成されている。それぞれのファセット面と底 面との間に, ボトムエッジ（BE）とファセット面同士 のトップエッジ（TE）が存在している。Fig. 6 (c) に, フラッシング後の 3D-Si 傾斜構造試料からの RHEED 像 を示す。 DB の直上に表面からの $16 \times 2$, 左上にファセ ット (111) 面からの $7 \times 7$ 回折パターンが観察される。 ファセット面からの回折パターンは破線で示したシャド ウエッジが表面に対する傾斜角〜 $35^{\circ}$ 傾いており， スポ ットも面法線方向に伸びていることも確認できる。この ことからこの 3D-Siに扔いても, 表面, ファセット面と もに原子レベルで平坦であることがわかる。

次に, この平坦な $3 \mathrm{D}-\mathrm{Si}$ 上に金を $10 \mathrm{~nm}$ 蒸着しサイズ が $\mathrm{W} \times \mathrm{L} \mu \mathrm{m}^{2} \quad(\mathrm{~W}=2-50 \mu \mathrm{m}, \mathrm{L}=100 \mu \mathrm{m})$ の電極パ夕 ーン構造を作製し，その伝導特性を測定した。試料の概 要図は Fig. 6 (d) の扦入図に示す通りで, この試料に 対して $\mathrm{BE}$ 及び $\mathrm{TE} に$ 平行配置, 拈よび垂直配置の伝導 測定結果を Fig. 6 (d) に示す。 $\mathrm{W}=5 \mu \mathrm{m}$ でエッジに平 行な場合（回）と比べ，垂直方向の伝導（○）では抵抗 值が 5 倍上昇している。 $\mathrm{W}=2 \mu \mathrm{m}$ の場合でも, 平行配 置（ム）での抵抗值は垂直配置 $(\times)$ での抵抗值よりも 5 倍高く, すべての細線幅でエッジに平行な場合と比べ
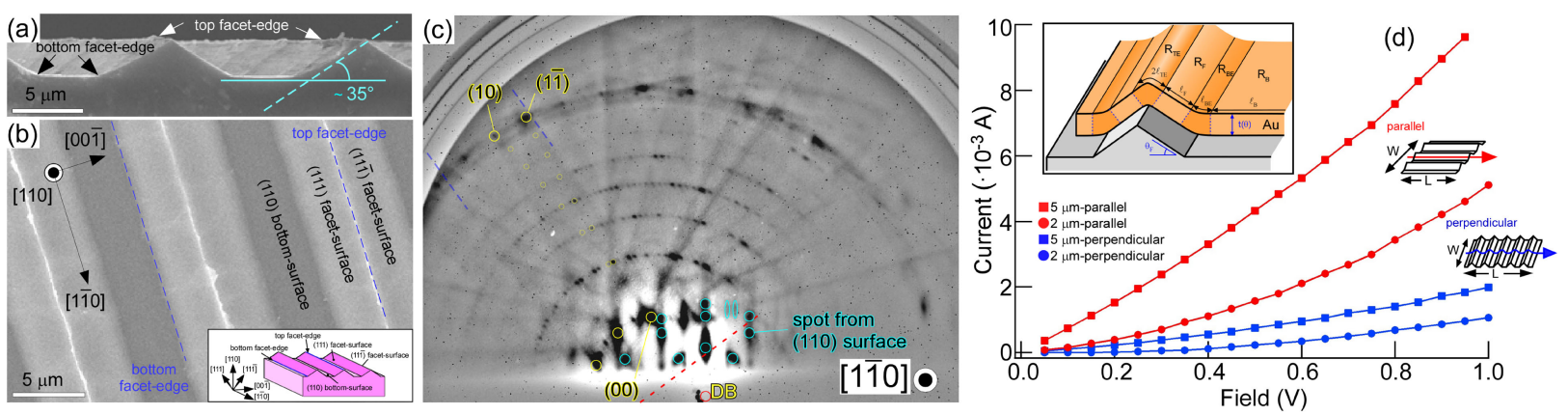

Fig. 6. (color online). (a) Typical cross-sectional SEM images for a $\{111\}$ facet sample after dry etching and wet etching. (b) Top-view SEM image of the sample in (a). The inset shows schematic of a sample. (c) Typical RHEED pattern for the $\{111\}$ facet sample. (d) Current vs voltage curves of Au wires with the channel area (W $\times$ L) of $2 \times 100$ $\mu \mathrm{m}^{2}$ and $5 \times 100 \mu \mathrm{m}^{2}$ in the parallel $(/ /)$ and perpendicular $(\perp)$ configurations at $100 \mathrm{~K}$. The inset shows schematic illustration of the Au film on the $\operatorname{Si}\{111\}$ facet sample. Adapted from Ref 16. 
垂直方向の伝導では 3-10 倍に抵抗值が上昇することが 分かった。これは 2-3 nm のファセット端領域での位相 不整合に由来する伝導電子の散乱が起き, エッジで抵抗 $\left(\mathrm{R}_{\mathrm{TE}}, \mathrm{R}_{\mathrm{BE}}\right)$ が 1-2 桁上昇するためであると考えられ $る^{16)}$ 。この結果は, 構造幾何学に関連した伝導特性が 3D 構造では現れることを示している。つまり我々の結 果は, 立体デバイス化には 3D 構造由来の物性（立体接 合金属の抵抗率）がデバイス特性に及ぼす影響を考慮す る必要があるということを明示している。

\section{4. ま と め}

これまで，Si の三次元パターニングは工業分野で積極 的に開発され, 現段階でのパターニングの精度 : $3 \sigma \sim 2$ $\mathrm{nm}$ はシビアに性能劣化をもたらしてはいない。しかし， 2020 年には到達する $10 \mathrm{~nm}$ 以下の領域では, 1-2 nm の 側面のラフネスがデバイスの性能を左右する重大なファ クターとなる。これまで $2 \mathrm{D}$ 表面を制御掞よび評価する ための技術であった「表面科学」で使われてきた RHEED・STM といった表面評価手法を三次元に展開さ せることで，経験的に行われていた立体造形技術を高度 に発展させ，垂直や傾斜側面といった様々な3D-Si 構造 の立体側面の評価に成功した。これによって，作製した 3D-Si の側面が原子レベルで平坦であることやその平坦 な立体側面に蒸着した金属が表面と同様に超構造を取る ことも明らかになり, 表面同様に側面やファセット面も 制御できることがわかった。乱れの無い3D 立体構造造 形は, 新たなレベルの物性研究を可能とする。なぜなら 物性を決める電子，スピン，電荷などには集団系に由来 したナノサイズの特性長が存在するが，形状・次元性・ サイズを精密に制御したナノ構造体において物性を顕在 化, 言い換えると擾乱されない純粋化した物性の取り出

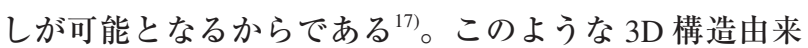
の物性を調べることは, 近い将来, 3D 構造上の原子レ ベルでの完全なナノスケール構造デバイスといった新し い次元でのモノづくりを実現するためには必要不可欠で ある。本研究は，その第一歩であると信じている。

\section{文献}

1) G.E. Moore : Electronics 38, 114 (1965).

2) K. Takayanagi, Y. Tanishiro, S. Takahashi and M. Takahashi : Surf. Sci. 164, 367 (1985).

3) S. Ino : Jpn. J. Appl. Phys. 16, 891 (1977).

4) D.J. Chadi : Phys. Rev. Lett. 43, 43 (1979).

5) Y. Yamamoto, S. Ino and T. Ichikawa : Jpn. J. Appl. Phys. 25, L331 (1986).

6) F. Larmer and P. Schilp : "Method of anisotropically etching silicon,” German Patent DE 4241045 (1994).

7) M. Nakagawa, K. Kobayashi, A.N. Hattori, S. Ito, N. Hiroshiba, S. Kubo and H. Tanaka : Langmuir 31, 4188 (2015).

8) A. Ichimiya and P.I. Cohen (Eds.) : "Reflection High Energy Electron Diffraction" (Cambridge, Cambridge University Press, 2004).

9) H. Yamatani, K. Hattori, T. Matsuta, T. Ito, T. Nohno, M. Hori, Y. Miyatake, S. Konno, T. Tanaka, Y. Hamada, H. Katagiri, M. Hibi, T. Miyai, M. Hashimoto, K. Kataoka, T. Tatsuta, A.N. Hattori, N. Higashi, M. Honda, N. Masunaga, H. Mino, S. Yasui, J. Nayeem, T. Shimizu, N. Takahashi, Y. Kato, C. Sakai, M. Yoshimura, S.N. Takeda, F. Matsui and H. Daimon : Surf. Sci. 601, 5284 (2007).

10) A.N. Hattori, K. Hattori, S. Takemoto, H. Daimon and H. Tanaka : Surf. Sci. 644, 86 (2016).

11) H. Yang, A.N. Hattori, A. Ohata, S. Takemoto, K. Hattori, H. Daimon and H. Tanaka : Jpn. J. Appl. Phys. 56, 111301 (2017).

12) A.N. Hattori, S. Takemoto, K. Hattori, H. Daimon and H. Tanaka : Appl. Phys. Express 9, 085501 (2016).

13) B. Feldman, R. Deng and S.T. Dunham : J. Appl. Phys. 103, 113715 (2008).

14) E. Buitrago, M. Fernández-Bolaños, S. Rigante, C.F. Zilch, N.S. Schröter, A.M. Nightingale and A.M. Ionescu : Sens. Actuators, B 193, 400 (2014).

15) N.A. Lanzillo, O.D. Restrepo, P.S. Bhosale, E.C. Silva, C.-C. Yang, B.Y. Kim, T. Spooner, T. Standaert, C. Child, G. Bonilla and K.V.R.M. Murali : Appl. Phys. Lett. 112, 163107 (2018).

16) S. Takemoto, A.N. Hattori, K. Hattori, H. Tanaka and H. Daimon : Jpn. J. Appl. Phys. 57, 090303 (2018).

17) A.N. Hattori, Y. Fujiwara, K. Fujiwara, T.V.A. Nguyen, T. Nakamura, M. Ichimiya, M. Ashida and H. Tanaka : Nano Lett. 15, 4322 (2015). 